\title{
APLIKASI TEKNOLOGI MESIN BERKAS ELEKTRON PADA PROSES PEWARNAAN BATIK KATUN DENGAN PEWARNA ALAMI MENGGUNAKAN METODE CURING
}

\section{APPLICATION OF ELECTRON BEAM MACHINE TECHNOLOGY ON COTTON BATIK COLORING PROCESS WITH NATURAL DYES USING CURING METHOD}

\author{
Wiwien Andriyanti' ${ }^{1}$, Darsono ${ }^{1}$, Elin Nuraini', Lilin Indrayani'2, Mutiara Triwiswara ${ }^{2}$ \\ ${ }^{1}$ PSTA - BATAN, Jl. Babarsari kotak pos 6101 ykbb Yogyakarta \\ ${ }^{2}$ BBKB - Kementrian Perindustrian, Jl. Kusumanegara No.7, Semaki, Yogyakarta \\ wiwien@batan.go.id
}

Diterima 21 April 2020, diterima dalam bentuk perbaikan 30 April 2020, disetujui 4 Juni 2020

\begin{abstract}
ABSTRAK
APLIKASI TEKNOLOGI MESIN BERKAS ELEKTRON PADA PROSES PEWARNAAN BATIK KATUN DENGAN PEWARNA ALAMI MENGGUNAKAN METODE CURING. "Green batik" yang disematkan pada batik pewarna alam tidak sepenuhnya tepat karena proses pembuatannya masih menggunakan zat kimia yang mengandung logam berat seperti halnya pada proses pembuatan batik pewarna sintetis. Untuk mengatasi permasalahan lingkungan tersebut maka pada penelitian ini dilaporkan hasil iradiasi berkas elektron pada sampel batik pewarna alam. Metode penelitian yang dilakukan adalah dengan mencampurkan zat warna alam (tingi, jolawe, dan mahoni) dengan polimer, kemudian campuran ini digunakan untuk pewarnaan batik. Proses fiksasi dilakukan dengan mengiradiasi sampel batik menggunakan berkas elektron sehingga terjadi proses curing. Hasil penelitian menunjukkan proses fiksasi menggunakan iradiasi berkas elektron dapat digunakan sebagai alternatif dalam rangkaian proses pewarnaan batik karena prosesnya yang efektif dan efisien serta menghasilkan produk yang ramah lingkungan. Dosis iradiasi fiksasi, dalam hal ini waktu iradiasi, mempengaruhii kualitas ketahan luntur warna batik. Pada waktu iradiasi 60 detik, kain batik katun dengan pewarna tingi dicampur PEG (Polietilen Glikol) mempunyai kualitas lebih baik dibandingkan dengan pewarna jolawe dicampur PEG dan pewarna mahoni dicampur PEG. Pewarna tingi dicampur PEG pada batik katun mempunyai ketahanan luntur warna terhadap sinar dengan nilai grey scale (4), ketahanan luntur warna terhadap pencucian dan gosokan dengan nilai staining scale (4-5)
\end{abstract}

Kata kunci: batik, zat warna alam, fiksasi, berkas elektron, curing, ketahan luntur warna

\section{ABSTRACT}

APPLICATION OF ELECTRON BEAM MACHINE TECHNOLOGY ON COTTON BATIK COLORING PROCESS WITH NATURAL DYES USING CURING METHOD. "Green batik" labeled in natural dyes batik is not entirely correct because the manufacturing process still uses chemicals that contain heavy metals as well as in the process of making synthetic dyes batik. To overcome these environmental problems, this research reports the electron beam irradiation results on natural dyes batik samples. The research method has been carried out by mixing natural dyes (Ceriops tagal, Terminalia bellirica, and Swietenia mahagoni) with a polymer, then this mixture was is used for coloring batik. The fixation process is done by irradiating batik samples using an electron beam so that the curing process occured. The irradiation dose of fixation, in this case correlated with irradiation time, affects the quality of batik color fastness. At 60 seconds irradiation, cotton batik cloth with Ceriops tagal dye mixed with PEG (Polyethylene Glycol) has a better quality compared to Terminalia bellirica dye mixed with PEG and Swietenia mahagoni dye mixed with PEG. Ceriops tagal dyes mixed with PEG on cotton batik have color fastness to sun light with gray scale value (4), color fastness to washing and rubbing with staining scale value (4-5).

Keywords: batik, natural dyes, fixation, electron beam, curing, color fastness 


\section{PENDAHULUAN}

$B^{\text {ati }}$ atik merupakan salah satu kekayaan budaya Indonesia yang sudah ada sejak dulu dan perkembangan industrinya semakin meningkat setelah pada tanggal 2 Oktober 2009 batik diakui dunia dan ditetapkan sebagai World Heritage oleh UNESCO. Yogyakarta sebagai salah satu penghasil batik di Indonesia, pada peringatan 50 tahun World Craft Council (WCC) tanggal 18-23 Oktober 2014 di Dongyang, Provinsi Zhejiang, Tiongkok, mendapatkan kehormatan karena dinobatkan sebagai Kota Batik Dunia. Oleh karena itu, pemerintah Yogyakarta memberikan dorongan bagi pengrajin batik Yogyakarta untuk meningkatkan proses produksi batik yang ecofriendly agar dapat lebih diterima masyarakat internasional, dengan menggunakan pewarna alami dalam rantai produksi. Program batik dengan warna alami ini merupakan upaya pemerintah Yogyakarta untuk meminimalisir pencemaran lingkungan yang diakibatkan oleh pewarna kimia/sintetis sehingga mencapai produksi yang ecofriendly dan diterima di masyarakat internasional karena mampu memecahkan masalah lingkungan [1] [2]. Batik merupakan kerajinan tangan sebagai hasil pewarnaan secara perintangan menggunakan malam (lilin batik) panas sebagai perintang warna dengan alat utama pelekat lilin batik berupa canting tulis dan atau canting cap untuk membentuk motif tertentu yang memiliki makna [3]. Media yang digunakan untuk proses pembatikan biasanya menggunakan kain katun. Kain katun merupakan jenis kain yang terbuat dari serat kapas, dan mempunyai sifat mudah menyerap bahan alami maupun kimia.

Zat warna alami merupakan zat warna yang diperoleh dari alam, terdapat tiga jenis sumber zat warna alami, yaitu berasal dari tumbuhan, hewan, dan mineral [4]. Zat warna alami yang diperoleh dari tumbuhan atau zat warna mordan merupakan zat warna yang dapat bersenyawa dengan oksida-oksida logam dengan membentuk senyawa berwarna yang tidak larut dalam air [5]. Penerapan zat warna alami pada batik dengan menggunakan beberapa jenis tanaman pembawa warna telah banyak dilakukan, diantaranya adalah kulit kayu tingi (Ceriops tagal), jolawe (Terminalia bellirica) dan mahoni (Swietenia mahagoni (L.) Jacq). Warna alam tingi, jolawe dan mahoni merupakan jenis zat warna alam yang banyak digunakan untuk pewarnaan di industri batik karena dapat memberi arah warna coklat, kuning kehijauan dan merah kecoklatan yang kuat dengan pengulangan pencelupan [6]. Pewarnaan batik dengan zat warna alami menghasilkan produk batik dengan daya tarik pada karakteristik yang alami, unik, etnik, dan eksklusif, sehingga memiliki potensi pasar yang tinggi. Zat warna alami telah direkomendasikan sebagai pewarna yang ramah baik bagi lingkungan maupun kesehatan karena kandungan komponen alaminya mempunyai nilai beban pencemaran yang relatif rendah, mudah terdegradasi secara biologis dan tidak beracun [7]. Oleh karena itu, penggunaan pewarna alami digiatkan kembali di seluruh dunia karena penggunaan zat warna sintetis dapat menyebabkan pencemaran lingkungan apabila tidak dikelola dengan baik dan benar. Dampak yang ditimbulkan adalah penipisan oksigen terlarut, kualitas perairan menurun dan kematian makhluk hidup yang tinggal di dalamnya karena kekurangan oksigen atau terkontaminasi senyawa beracun. Haqiqi, et al.[8] dan Kant [9] mengatakan bahwa jika limbah zat warna sintetis mengalir ke dalam tanah, maka akan menyumbat pori-pori tanah yang berakibat pada hilangnya produktivitas tanah dan tekstur tanah mengeras karena bakteri tanah tidak mampu mendegradasi bahan kimia dari zat warna sintetis tersebut.

Dalam proses pewarnaan batik dikenal 2 (dua) macam zat warna antara lain zat warna sintetis (ZWS) dan zat warna alami (ZWA). ZWS merupakan zat warna yang berasal dari reaksi zat-zat kimia sedangkan ZWA berasal dari bahan alam pada umumnya berasal dari tumbuhan (akar, batang, daun, kulit, bunga, dII). Keunggulan dari proses pewarnaan menggunakan ZWA dibanding dengan ZWS adalah sifatnya yang ramah lingkungan dan menghasilkan warna yg khas [10], [11]. Kelemahan dari penggunaan pewarna alami yaitu ketahanan luntur warna dan intensitas (ketuaan) warna yang relatif kurang baik, sehingga memerlukan bahan tambahan untuk mengikat warna supaya meningkatkan ketahanan terhadap luntur [11], [12]. Cara untuk meningkatkan ketahanan luntur warna adalah dengan menggunakan proses fiksasi. Fiksasi merupakan proses pencelupan yang bertujuan untuk memperkuat warna dan merubah zat warna alami sesuai dengan jenis logam yang mengikatnya serta mengunci zat warna yang telah masuk ke dalam serat agar warna yang dihasilkan tidak mudah pudar atau luntur [5], [11]. Fiksasi dilakukan dengan menambahkan bahan yang mengandung garam logam. Bahan fiksasi yang biasa digunakan antara lain tawas $\left[\mathrm{K}_{2} \mathrm{SO}_{4} \cdot \mathrm{Al}_{2}\left(\mathrm{SO}_{4}\right)_{3} \cdot 24 \mathrm{H}_{2} \mathrm{O}\right]$, kapur $\left[\mathrm{CaCO}_{3}\right]$, dan tunjung $\left(\mathrm{FeSO}_{4}\right)$. Di samping memperkuat ikatan, garam logam juga berfungsi untuk merubah arah zat warna alami sesuai dengan jenis garam logam yang mengikatnya. Namun kalau dicermati lebih detail pada proses pembuatan batik menggunakan pewarna 
ZWA juga masih menimbulkan permasalahan lingkungan karena dalam proses fiksasi masih menggunakan zat kimia yang mengandung garam logam berat.

Untuk mengatasi permasalahan lingkungan yang diakibatkan dari proses fiksasi pada pembuatan batik dengan ZWA yang menggunakan garam logam berat maka diusulkan metode proses fiksasi menggunakan iradiasi berkas elektron. Pada penelitian ini pewarna ZWA nantinya akan dicampurkan dengan polimer tertentu sehingga terbentuk dye-containing polymer yang kemudian digunakan untuk mewarnai batik. Batik yang telah diwarnai ini akan diradiasi menggunakan berkas elektron agar terjadi fiksasi. Ketika batik diradiasi menggunakan berkas elektron diharapkan akan terjadi proses curing. Curing adalah proses di mana reaksi kimia (seperti polimerisasi) atau aksi fisik (seperti penguapan) terjadi, menghasilkan perubahan fase cair ke fasa padat dengan ikatan yang rekat. Electron beam curing adalah suatu proses menggunakan radiasi berkas elektron untuk menginduksi reaksi kimia radiasi yaitu polimerisasi monomer dan oligomer-polimer ikatan silang dan perubahan fasa dari fase cair ke fasa padat. Curing banyak digunakan pada proses pelapisan (coating) misal warna pada substrat untuk membuat glossy paper [13]. Proses curing dengan iradiasi elektron dari Mesin Berkas Elektron (MBE) mempunyai beberapa kelebihan, diantaranya adalah kapasitas pemrosesan besar, luasan bahan yang akan dicuring dapat dikendalikan, efisiensi pemanfaatan energi yang tinggi, kemudahan proses dan tingkat keselamatan radiasi yang cukup tinggi sehingga menghasilkan produk yang efektif dan efiisien.

Dengan teknik fiksasi menggunakan iradiasi berkas elektron akan dihasilkan kain batik yang ramah lingkungan dan mendukung program "Green Eco" karena tidak menimbulkan limbah logam berat dalam proses pembuatannya. Teknik fiksasi dengan iradiator elektron sangat mendukung program "Green Eco" karena pewarna ZWA yang terbuat dari tumbuhan bisa dipakai sampai habis. Pewarna alami memiliki konsentrat warna yang stabil, sehingga pewarna itu bisa dipakai sampai habis dan sisa limbah padatnya yang berupa hasil rebusan bisa digunakan kembali sebagai pupuk kompos. Dengan demikian dimungkinkan mengembangkan produk budaya yang ramah lingkungan.

\section{METODOLOGI}

Bahan-bahan yang digunakan adalah kain batik katun, pewarna alami (Tingi, Jolawe, dan Mahoni), Polietilen Glikol (PEG), dan aquadest.

Alat

Peralatan yang digunakan dalam penelitian ini adalah peralatan gelas, neraca analitik, seperangkat alat Mesin Berkas Elektron (MBE) $350 \mathrm{keV} / 10 \mathrm{~mA}$ dan alat pengujian ketahanan luntur warna (Grey Scale, Staining Scale, dan Crockmeter).

\section{Cara kerja}

Proses dimulai dengan membuat larutan Polietilen Glikol (PEG) dengan cara menimbang polimer sebanyak 25 gram kemudian dilarutkan dalam $100 \mathrm{ml}$ aquadest. Selanjutnya membuat larutan campuran pewarna ZWA dan polimer dengan perbandingan volume 1:3. Kain batik katun yang telah dipotong dilakukan proses pewarnaan dengan menggunakan zat pewarna alam. Kain batik katun dicelupkan ke dalam larutan campuran pewarna ZWA dan polimer selama 30 menit pada temperatur kamar. Selanjutnya kain batik katun diangkat dan dikeringkan dengan cara diangin-anginkan dan tidak terkena sinar matahari langsung. Pencelupan dilakukan masing-masing 3 kali celupan dan pengeringan. Kain batik katun yang sudah agak kering kemudian dilakukan proses iradiasi menggunakan Mesin Berkas Elektron. Sampel diiradiasi menggunakan Mesin Berkas Elektron milik PSTA-BATAN Yogyakarta dengan energi elektron $300 \mathrm{keV}$ dan arus berkas $600 \mu \mathrm{A}$ yang tetap serta variasi waktu 30,45 , dan 60 detik sehingga didapatkan dosis yang diinginkan. Kain batik katun yang sudah dilakukan proses iradiasi siap untuk dilakukan pengujian.

\section{Pengujian}

Pengujian kain batik katun meliputi ketahanan luntur warna terhadap sinar matahari, ketahanan luntur warna pada pencucian sabun \& uji penodaan terhadap kain putih, dan ketahanan luntur warna terhadap gosokan kain. Ketahanan luntur warna terhadap pencucian dinyatakan dengan adanya perubahan warna dan penodaan 
warna pada kain batik. Pengujian penodaan dilakukan pada kain kapas, hal ini sesuai dengan media batik yang digunakan pada penelitian menggunakan kain katun. Pengujian ketahanan luntur warna terhadap pencucian berdasar pada SNI ISO 105-C06:2010 Tekstil - Cara uji tahan luntur warna - Bagian C06: tahan luntur warna terhadap pencucian rumah tangga dan komersial [14]. Pengujian terhadap sinar berdasar pada SNI ISO 105B01:2010 Tekstil - Cara uji tahan luntur warna - Bagian B01: Tahan luntur warna terhadap sinar terang hari [15]. Pengujian terhadap gosokan kain berdasar pada SNI ISO 105-X12: 2012 Tekstil - Cara uji tahan luntur warna Bagian X12: Tahan luntur warna terhadap gosokan [16].

Standar pengujian yang telah dikenal adalah standar yang dibuat oleh Society of Dyers and Colourists (S.D.C) di Inggris dan Amerika Serikat, yaitu berupa standar gray scale untuk perubahan warna karena kelunturan warna dan standar staining scale untuk perubahan warna karena penodaan pada kain putih. Pada gray scale, penilaian tahan luntur warna dan perubahan warna yang sesuai, dilakukan dengan membandingkan perbedaan pada contoh yang telah diuji dengan contoh asli terhadap perbedaan yang sesuai dengan standar perubahan warna yang digambarkan oleh gray scale dan dinyatakan dengan nilai 5 sampai 1 . Pada staining scale penilaian penodaan pada kain putih di dalam penggujian tahan luntur warna dilakukan dengan membandingkan perbedaan warna dari kain putih yang dinodai dan tidak dinodai. Penilaian penodaan warna pada staining scale dinyatakan juga dengan nilai 5 sampai 1. Nilai 5 diberikan apabila terdapat perbedaan warna antara kain putih asli dengan kain yang diuji [17], [18].

\section{HASIL DAN PEMBAHASAN}

Suatu bahan akan memiliki kualitas warna yang baik jika memiliki ketahanan luntur warna yang baik. Tingkat ketahanan luntur warna pada kain batik dinilai dengan perubahan warna yang diukur menggunakan alat gray scale dan penodaan pada kain putih diukur menggunakan staining scale. Wahidatun Nurul Azizah [17] menjelaskan bahwa standar gray scale (skala abu-abu) dan staining scale (skala penodaan) digunakan untuk menilai perubahan warna yang terjadi pada pengujian tahan luntur warna terhadap pencucian, keringat, gosokan, seterika, sinar matahari, obat-obat kimia, air laut dan sebagainya. Hasil pengujian Tahan Luntur Warna (TLW) pada campuran pewarna ZWA dan polimer dengan variasi waktu disajikan pada Tabel 1.

Tabel 1. Hasil pengujian Tahan Luntur Warna (TLW) pada campuran pewarna ZWA dan polimer

\begin{tabular}{|c|c|c|c|c|c|}
\hline \multirow{2}{*}{ Kode sampel } & \multirow{2}{*}{$\begin{array}{l}\text { Nilai TLW thd } \\
\text { Sinar Matahari } \\
\text { (Gray Scale) }\end{array}$} & \multicolumn{2}{|c|}{$\begin{array}{c}\text { Nilai Uji TLW thd Pencucian Sabun \& } \\
\text { Uji Penodaan thd Kain Putih }\end{array}$} & \multicolumn{2}{|c|}{ Nilai Uji TLW thd Gosokan Kain } \\
\hline & & $\begin{array}{c}\text { Kelunturan (Grey } \\
\text { Scale) }\end{array}$ & $\begin{array}{c}\text { Penodaan } \\
\text { (Staining Scale) }\end{array}$ & $\begin{array}{l}\text { Gosok Kering } \\
\text { (Staining Scale) }\end{array}$ & $\begin{array}{l}\text { Gosok Basah } \\
\text { (Staining Scale) }\end{array}$ \\
\hline Non iradiasi & 4 (baik) & 4 (baik) & 3-4 (cukup baik) & 4 (baik) & 3-4 (cukup baik) \\
\hline Tingi + PEG t: 30" & 3-4 (cukup baik) & 3 (cukup) & 3-4 (cukup baik) & 4-5 (baik) & 4 (baik) \\
\hline Tingi + PEG t: 45" & 4 (baik) & 4 (baik) & 4-5 (baik) & 4-5 (baik) & 4 (baik) \\
\hline Tingi + PEG t: 60" & 4 (baik) & 4 (baik) & 4-5 (baik) & 4-5 (baik) & 4 (baik) \\
\hline Jolawe + PEG t: 60" & 4 (baik) & 3-4 (cukup baik) & 4-5 (baik) & 4-5 (baik) & 4 (baik) \\
\hline Mahoni + PEG t: 60" & 3-4 (cukup baik) & 4 (baik) & 4-5 (baik) & 4-5 (baik) & 4 (baik) \\
\hline
\end{tabular}

\section{Uji Tahan Luntur Warna terhadap Sinar Matahari}

Berdasarkan Tabel 1 diperoleh nilai tahan TLW terhadap sinar matahari memberikan hasil yang bervariasi nilai 3-4 (cukup baik) sampai nilai 4 (baik). Hasil pengujian terlihat bahwa untuk pewarna tingi dengan tambahan polimer PEG pada waktu iradiasi 30 detik tidak menunjukkan peningkatan daya tahan luntur apabila dibandingkan dengan kain non iradiasi. Untuk pewarna tingi dengan tambahan polimer PEG pada waktu iradiasi yang lain yaitu 45 dan 60 detik menunjukkan nilai 4 dengan kategori baik yang menunjukkan terjadinya peningkatan ketahanan luntur warna apabila dibandingkan pada waktu proses 30 detik. Namun jika dibandingkan dengan proses non 
iradiasi, ZWA dengan tambahan polimer belum menunjukkan peningkatan ketahanan luntur warna. Ketahanan luntur warna yang baik berarti pada saat dijemur terkena sinar matahari, sampel kain yang dievaluasi perubahan warnanya menggunakan grey scale menunjukkan perubahan warna yang kurang jelas dimana perbedaan warna contoh uji sebelum dan sesudah dijemur tidak menunjukkan banyak perbedaan warna. Kualitas ketahanan luntur warna terhadap sinar (terang hari) dengan indikator nilai tahan sinar sangat tergantung dari nilai perubahan warna yaitu adanya perbedaan warna yang jelas antara warna contoh uji yang sebelum dijemur dengan contoh uji yang sesudah dijemur. Hal ini juga berkaitan erat dengan daya reaktif zat warna yang menunjukkan kemampuan zat warna masuk ke dalam serat. Menurut Rini Pujiarti [12], sinar matahari yang mengandung sinar ultraviolet dan energi panas yang menyerang rantai molekul zat warna dapat menyebabkan rantai molekul zat warna putus. Akibat dari rantai yang putus, dapat menyebabkan warna pudar (luntur) karena gugus pembawa warna pada molekul zat warna tidak aktif. Nilai ketahanan luntur warna terhadap sinar matahari lebih ditentukan oleh stabil dan tidaknya struktur molekul zat warna apabila terkena energi panas dan sinar ultraviolet.

Hasil penelitian ini didukung oleh penelitian Dwi Suheryanto \& Tri Haryanto [19] yang menyatakan bahwa fungsi fiksator selain untuk menimbulkan warna juga untuk memperkuat ikatan antar serat dan warna sehingga mencegah dehidrasi pigmen warna. Selain itu, penelitian Failisnur dan Sofyan [20] menyatakan bahwa ketahanan luntur warna dapat diperbaiki melalui proses fiksasi dimana setelah zat warna terdifusi ke dalam larutan kemudian terserap (absorbsi) menempel ke permukaan serat, lalu terserap dan terdifusi ke pusat serat tekstil. Proses fiksasi juga dapat meningkatkan sifat ketahanan luntur warna serat kain terhadap cahaya [21], [22]. Supaya zat warna terkunci di dalam serat maka diperlukan proses fiksasi yang menggunakan logam fiksator. Bedanya dalam penelitian ini, logam fiksator diganti dengan berkas elektron. Elektron berperan dalam proses ikatan silang (crosslinking) yang mengikat ZWA ke dalam kain. Adanya proses cross-linking inilah yang memperkuat ikatan antar serat dan warna sehingga meningkatkan sifat ketahanan luntur warna. Variasi waktu proses iradiasi menggunakan Mesin Berkas Elektron yang dilakukan yaitu dengan waktu 30, 45, dan 60 detik menunjukkan hasil yang kurang optimal pada waktu iradiasi 30 detik dan mulai menunjukkan peningkatan mulai waktu iradiasi 45 dan 60 detik jika dibandingkan dengan waktu proses 30 detik. Namun jika dibandingkan dengan kain non iradiasi, ZWA dengan tambahan polimer belum menunjukkan peningkatan ketahanan luntur warna. Hasil uji ketahanan luntur warna yang kurang baik pada waktu 30 detik dikarenakan pada dosis rendah (30 detik) zat warna alam dengan campuran polimer belum mengalami proses curing secara keseluruhan.

\section{Uji Tahan Luntur Warna terhadap Pencucian Sabun \& Uji Penodaan thd Kain Putih}

Hasil uji TLW terhadap pencucian sabun \& uji penodaan terhadap kain putih pada ZWA (tingi, jolawe dan mahoni) dengan tambahan polimer PEG menunjukkan nilai 4 (baik) untuk uji kelunturan (Gray Scale) dan nilai 4-5 (baik) untuk uji penodaan (Staining Scale). Nilai uji kelunturan dan penodaan yang berbeda ditunjukkan pada ZWA tingi dengan tambahan polimer pada waktu iradiasi 30 detik. Waktu iradiasi 30 detik menggunakan mesin berkas elektron ternyata kurang optimal untuk proses curing pada kain batik katun. Sedangkan waktu iradiasi pada 45 dan 60 detik didapatkan peningkatan ketahanan luntur warna jika dibandingkan dengan kain non iradiasi kecuali pada sampel ZWA jolawe pada waktu iradiasi 60 detik menunjukkan penurunan nilai kelunturan walaupun termasuk dalam kategori 3-4 (cukup baik). Dalam hal ini diduga pada waktu iradiasi 45 detik terjadi proses cross-linking yang optimal antara zat warna alam polimer dengan katun, sedangkan untuk waktu iradiasi 60 detik diduga telah terjadi proses degradasi. Perlakuan dan parameter proses yang sama pada ZWA yang berbeda ternyata memberikan perbedaan hasil pengujian ketahanan luntur warna.

Hal ini sesuai dengan penelitian Rizka Amalia [11] dan Ibnu Ahmad [23] yang menyatakan bahwa ketahanan luntur terhadap pencucian yang lebih kuat pada kain berkaitan dengan terjadinya ikatan zat warna yang mampu masuk ke dalam serat kain secara maksimum dan berikatan kuat dengan serat kain. Kekuatan serat kapas dipengaruhi oleh kadar selulosa dalam serat kain katun yang mampu menyerap zat warna alami, sehingga pada kain katun mampu mengikat warna dengan baik sehingga tahan dalam pencucian dan sinar terang hari. Hal ini sesuai dengan pendapat Titik Pujilestari [5] yang menyatakan bahwa serat kapas struktur kimianya merupakan senyawa benzena yang mengandung gugus hidroksil yang mudah menyerap air yang sebagian besar terdiri dari selulose (komponen utama), lemak, malam dan pektin. 


\section{Uji Tahan Luntur Warna terhadap Gosokan Kain}

Nilai uji TLW terhadap gosokan kain baik gosok kering dan gosok basah menunjukkan peningkatan ketahanan luntur warna jika dibandingkan dengan kain non iradiasi. Nilai uji TLW untuk gosok kering didapatkan nilai 4-5 (baik) dan gosok basah menunjukkan nilai 4 (baik) yang menunjukkan kain yang diuji mempunyai nilai ketahanan luntur yang baik. Hal ini sesuai dengan SNI ISO 8303:2016 [24] tentang syarat mutu batik cap pada bahan kain batik untuk jenis uji gosokan baik gosok kering maupun gosok basah minimum mempunyai nilai staining scale sebesar 4.

Proses curing yang terjadi antara zat warna alam polimer menggunakan berkas elektron mempunyai mekanisme yang berbeda dengan pembuatan batik ZWA yang menggunakan garam logam berat. Bagian penting pada proses curing adalah interaksi elektron dengan bahan yang diradiasi. Pada proses curing menggunakan berkas elektron akan terjadi interaksi satu sama lain sehingga membentuk ikatan silang (cross-linking) antara unsur-unsur ZWA dan polimer yang dicampurkan. Adanya proses cross-linking inilah yang menyebabkan unsurunsur ZWA dan polimer saling berikatan kuat sehingga pada saat uji ketahanan luntur warna kain iradiasi akan lebih tahan terhadap gosokan daripada kain non iradiasi.

Pengujian TLW sangat dipengaruhi dari proses yang dilakukan baik dari proses awal seperti pemilihan konsentrasi polimer yang digunakan sebagai pengganti proses fiksasi lama yang menggunakan bahan kimia seperti tawas, kapur, atau tunjung, proses pencelupan ZWA dan waktu iradiasi sampel uji. Menurut Rizka Amalia [11], pada konsentrasi zat fiksasi yang berbeda menunjukkan pengaruh yang berbeda dimana penggunaan konsentrasi bahan fiksasi yang lebih tinggi ( $25 \%$ dan $45 \%)$, nilai grey scale dan staining scale akan semakin baik. Proses pencelupan juga merupakan salah satu faktor yang dapat menentukan kualitas, ketuaan dan arah warna batik. Oleh karena itu, perlu kecermatan dan kehati-hatian dalam pencelupan warna pada batik [23]. Lamanya waktu pencelupan juga berpengaruh terhadap intensitas warna yang dihasilkan. Semakin lama proses pencelupan akan meningkatkan kekuatan warna yang ditimbulkan. Penyerapan zat warna ke dalam serat membutuhkan tahapan dan langkah sampai dicapainya proses kesetimbangan. Mulai dari bergeraknya larutan zat warna agar menempel pada bahan (migrasi), selanjutnya terdorongnya zat warna menempel di permukaan serat bahan (adsorpsi), kemudian berdifusi dari permukaaan bahan menuju sentral serat sampai terjadi kesetimbangan (penetrasi) [17] [25]. Menurut Titiek Pujilestari [26], penyerapan pewarna alam tingi oleh kain katun sampai pada titik kejenuhan serat dicapai pada perlakuan pencelupan sebanyak 11 kali. Hal terakhir yang perlu diperhatikan adalah penentuan waktu iradiasi sampel uji menggunakan Mesin Berkas Elektron untuk menginduksi reaksi kimia radiasi harus tepat sehingga terjadi proses polimerisasi antara unsur-unsur dalam polimer yang ditambahkan dengan unsur-unsur dalam ZWA.

Hasil penelitian ini menunjukkan proses fiksasi menggunakan iradisi berkas elektron dapat digunakan sebagai alternatif dalam rangkaian proses pewarnaan batik karena prosesnya yang efektif dan efisien serta menghasilkan produk yang ramah lingkungan. Proses efektif dan efisien karena proses fiksasi dapat diatur sesuai kebutuhan dan berlangsung dengan cepat. Penggunaan polimer sebagai bahan penganti logam berat memberikan pengaruh yang cukup baik pada akhir proses karena tidak menimbulkan pencemaran pada lingkungan.

\section{KESIMPULAN}

Metode iradiasi berkas elektron pada proses pewarnaan batik menggunakan zat pewarna alam dapat digunakan sebagai metode alternatif fiksasi. Dosis iradiasi fiksasi, dalam hal ini waktu iradiasi, mempengaruhii kualitas ketahan luntur warna batik. Kain batik katun dengan pewarna alam tingi dicampur PEG difiksasi dengan waktu iradiasi elektron 60 detik mempunyai ketahanan luntur warna yang lebih baik dibandingkan dengan pewarna alam jolawe dicampur PEG dan mahoni dicampur PEG. Pada waktu iradiasi 60 detik, kain batik katun dengan pewarna alam tingi dicampur PEG mempunyai ketahanan luntur warna terhadap sinar dengan nilai grey scale (4), ketahanan luntur warna terhadap pencucian dan gosokan dengan nilai staining scale (4-5). 


\section{UCAPAN TERIMA KASIH}

Penulis mengucapkan terima kasih pada penanggungjawab fasilitas laboratorium Mesin Berkas Elektron di Pusat Sains dan Teknologi Akselerator serta kepada Bpk. Sukaryono dan Bpk. Saefurrochman atas bantuannya dalam penelitian ini.

\section{DAFTAR PUSTAKA}

[1]. D. P. Rahayu, "Peta Politik Industri Batik Yogyakarta dan Dampaknya dalam Sistem Perburuhan Batik di Yogyakarta," J. Kaji. Ruang Sos., vol. 3, no. 1, pp. 30-45, 2019, doi: 10.21776/ub.sosiologi.jkrsb.2019.003.1.03.

[2]. R. W. Tanjung, S. Suryaningsum, A. N. Maharani, and R. Hendri, "Batik Yogyakarta Dalam Era Revolusi Industri 4 . 0," Pros. Semin. Nas. Ind. Kerajinan dan Batik, 2019.

[3]. Badan Standarisasi Nasional, "SNI 0239:2014 Batik - Pengertian dan istilah." 2014.

[4]. T. Alemayehu and Z. Teklemariam, "Application of Natural Dyes on Textile : A Review," Int. J. Res. Granthaalayah I, vol. 2, no. 2, pp. 61-68, 2014.

[5]. T. Pujilestari, "Pengaruh Ekstraksi Zat Warna Alam dan Fiksasi Terhadap Ketahanan Luntur pada Kain Batik Katun," Din. Kerajinan dan Batik, vol. 31, no. 1, pp. 1-9, 2014.

[6]. P. A. Handayani and I. Maulana, "Pewarna Alami Batik Dari Kulit Soga Tingi (Ceriops Tagal) Dengan Metode Ekstraksi," J. Bahan Alam Terbarukan, vol. 2, no. 2, pp. 1-6, 2014, doi: 10.15294/jbat.v2i2.2793.

[7]. N. Rungruangkitkrai and M. Rattanaphol, "Eco-Friendly of Textiles Dyeing and Printing with Natural Dyes," RMUTP Int. Conf. Text. Fash., no. July 3-4, Bangkok Thailand, 2012.

[8]. A. K. Haqiqi, M. P. Aji, and A. Yuliyanto, "Ekstraksi Daun Pepaya (Carica Papaya L.) Sebagai Zat Pewarna Alami Pada Kain Batik," Indones. J. Nat. Sci. Educ., vol. 1, no. 1, pp. 13-17, 2018, doi: 10.31002/nse.v1i1.204.

[9]. R. Kant, "Textile dyeing and printing industry: An environmental hazard," Nat. Sci., vol. 4, no. 1, pp. 22-26, 2012.

[10].Yernisa, E. Gumbira-Sa'id, and K. Syamsu, "Aplikasi Pewarna Bubuk Alami dari Ekstrak Biji Pinang (Areca Catechu L.) pada Pewarnaan Sabun Transparan,” J. Teknol. Ind. Pertan., vol. 23, no. 3, pp. 190-198, 2013.

[11].R. Amalia and I. Akhtamimi, "Studi Pengaruh Jenis dan Konsentrasi Zat Fiksasi Terhadap Kualitas Warna Kain Batik dengan Pewarna Alam Limbah Kulit Buah Rambutan (Nephelium lappaceum)," Din. Kerajinan dan Batik Maj. Ilm., vol. 33, no. 2, pp. 85-92, 2016, doi: 10.22322/dkb.v33i2.1474.

[12].R. Pujiarti, D. P. Sari, Kasmudjo, and T. B. Widowati, "Kualitas Pewarnaan Batik yang Dihasilkan dari Perbedaan Konsentrasi dan Bahan Fiksasi Bahan Pewarna Daun Mangga Arum Manis (Mangifera Indica LINN)," in Prosiding Seminar Nasional MAPEKI XII, 2009, pp. 932-940.

[13].I. Rangwalla, "Development in Low Voltage EB Curing For High Product Throughput Applications," Radtech Conf., no. 3, pp. 35-39, 2014.

[14].Badan Standarisasi Nasional, "Tekstil - Cara uji tahan luntur warna - Bagian C06 : Tahan luntur warna terhadap pencucian rumah tangga dan komersial," 2010.

[15].Badan Standarisasi Nasional, "Tekstil - Cara uji tahan luntur - Bagian B01: Tahan luntur warna terhadap sinar: Sinar terang hari." 2010.

[16].Badan Standarisasi Nasional, "SNI ISO 105-X12:2012 Tekstil - Cara uji tahan luntur - Bagian X12: Tahan luntur warna terhadap gosokan." 2012.

[17].W. N. Azizah, "Pengaruh Jenis Zat Fiksasi Terhadap Kualitas Pewarnaan Kain Mori Primissima Dengan Zat Warna Euphorbia," Tugas Akhir, Progr. Stud. Pendidik. Tek. Busana FT UNY, vol., no., 2018, doi: 10.1017/CBO9781107415324.004.

[18].T. Rohmawati and A. Kusumastuti, "Potensi Gulma Babandotan (Ageratum Conyzoides L.) sebagai Pewarna Alam Kain Katun Primissima Menggunakan Mordan Jeruk Nipis, Tawas, Kapur Tohor, dan Tunjung," TEKNOBUGA J. Teknol. Busana dan Boga, vol. 7, no. 2, pp. 133-138, 2019. 
[19].D. Suheryanto and T. Haryanto, "Pengaruh Konsentrasi Tawas Terhadap Ketuaan dan Ketahanan Luntur Warna pada Pencelupan Kain Sutera dengan Zat Warna Gambir," Din. Kerajinan dan Batik, vol. 25, pp. 916, 2008.

[20].Failisnur and Sofyan, "Sifat Tahan Luntur dan Intensitas Warna Kain Sutera dengan Pewarna Alam Gambir (Uncaria gambir Roxb) Pada Kondisi Pencelupan dan Jenis Fiksator yang Berbeda," J. Litbang Ind., vol. 4, no. 1, pp. 1-8, 2014.

[21].H. F. Mansour and S. Heffernan, "Environmental aspects on dyeing silk fabric with sticta coronata lichen using ultrasonic energy and mild mordants," Clean Technol. Environ. Policy, vol. 13, no. 1, pp. 207-213, 2011, doi: 10.1007/s10098-010-0296-2.

[22].M. N. Micheal, F. M. Tera, and S. F. Ibrahim, "Effect of chemical modification of cotton fabrics on dyeing properties," J. Appl. Polym. Sci., vol. 85, no. 9, pp. 1897-1903, 2002, doi: 10.1002/app.10740.

[23].I. A. Amerudin, "Kualitas Warna pada Kain Batik dari Beberapa Daun dengan Variasi Larutan Fiksasi," Publ. IIm. Jur. Biol. Fak. Kegur. dan IImu Pendidik., 2018, doi: 10.1017/CBO9781107415324.004.

[24].Badan Standarisasi Nasional, "SNI 8303:2016 Batik cap - Kain - Ciri, syarat mutu dan metode uji," 2016.

[25].F. Failisnur and S. Sofyan, "Pengaruh Suhu dan Lama Pencelupan Benang Katun pada Pewarnaan Alami dengan Ekstrak Gambir (Uncaria gambir Roxb)," J. Litbang Ind., vol. 6, no. 1, p. 25, 2016, doi: 10.24960/jli.v6i1.716.25-37.

[26].T. Pujilestari, "Optimasi Pencelupan Kain Batik Katun dengan Pewarna Alam Tingi (Ceriops tagal) dan Indigofera Sp," Din. Kerajinan dan Batik Maj. IIm., vol. 34, no. 1, pp. 53-62, 2017, doi: 10.22322/dkb.v34i1.2606. 